\title{
Acute yellow oleander (Thevetia peruviana) poisoning: cardiac arrhythmias, electrolyte disturbances, and serum cardiac glycoside concentrations on presentation to hospital
}

\author{
M Eddleston, C A Ariaratnam, L Sjöström, S Jayalath, K Rajakanthan, S Rajapakse, \\ D Colbert, W P Meyer, G Perera, S Attapattu, S A M Kularatne, M R Sheriff, D A Warrell
}

Centre for Tropical Medicine, Nuffield Department of Clinical Medicine, University of Oxford, Headington, Oxford OX3 9DU, UK

$M$ Eddleston

G Perera

D A Warrell

Department of Clinical Medicine, Faculty of Medicine, University of Colombo, Colombo, Sri Lanka

C A Ariaratnam

$S$ Jayalath

K Rajakanthan

S Rajapakse

M R Sheriff

Therapeutic

Antibodies Inc,

Medical College of St

Bartholomew's

Hospital, London EC1,

UK

L Sjöström

W P Meyer

Department of

Chemical Pathology,

Homerton Hospital,

London E9, UK

D Colbert

Anuradhapura

General Hospital,

Anuradhapura, Sri

Lanka

S Attapattu

S A M Kularatne

Correspondence to: Professor Warrell. email: david.warrell@ ndm.ox.ac.uk

Accepted 23 September 1999

\begin{abstract}
Objective-To describe the cardiac arrhythmias, electrolyte disturbances, and serum cardiac glycoside levels seen in patients presenting to hospital with acute yellow oleander (Thevetia peruviana) poisoning and to compare these with published reports of digitalis poisoning.

Design-Case series.

Setting-Medical wards of Anuradhapura District General Hospital, Sri Lanka, and coronary care unit of the Institute of Cardiology, National Hospital of Sri Lanka, Colombo, the national tertiary referral centre for cardiology.

Patients-351 patients with a history of oleander ingestion.

Measurements-ECG and blood sample analysis on admission.

Results-Most symptomatic patients had conduction defects affecting the sinus node, the atrioventricular (AV) node, or both. Patients showing cardiac arrhythmias that required transfer for specialised management had significantly higher mean serum cardiac glycoside and potassium but not magnesium concentrations. Although there was considerable overlap between groups, those with conduction defects affecting both sinus and AV nodes had significantly higher mean serum cardiac glycoside levels.

Conclusions-Most of these young previously healthy patients had conduction defects affecting the sinus or AV nodes. Relatively few had the atrial or ventricular tachyarrhythmias or ventricular ectopic beats that are typical of digoxin poisoning. Serious yellow oleander induced arrhythmias were associated with higher serum cardiac glycoside concentrations and hyperkalaemia but not with disturbances of magnesium.

(Heart 2000;83:301-306)
\end{abstract}

Keywords: oleander poisoning; arrhythmias; cardiac glycosides

The yellow oleander (Thevetia peruviana) is an ornamental tree of the Apocyanaceae family that is common throughout the tropics and subtropics. ${ }^{1}$ Its sap contains cardiac glycosides that are toxic to cardiac muscle and the autonomic nervous system. ${ }^{2}$ Ingestion of its seeds results in a clinical picture similar to that of digoxin overdose. ${ }^{3-5}$ Severely poisoned patients may die in dc shock resistant ventricular fibrillation. Many patients with moderate poisoning show $\mathrm{PR}$ interval prolongation and progression to atrioventricular (AV) dissociation.

Accidental poisonings occur throughout the tropics, particularly in children. ${ }^{267}$ Adults have died after consuming oleander leaves in herbal teas. ${ }^{8}$ However, deliberate ingestion of yellow oleander seeds has recently become a popular method of self harm in northern Sri Lanka. ${ }^{9} 10$ There are thousands of cases each year, with a case fatality rate of at least $10 \% .{ }^{9}$ Around $40 \%$ require specialised management and are transferred from secondary hospitals across the north to the Institute of Cardiology in Colombo for temporary pacing. ${ }^{9}$

We have been carrying out studies over the last three years in an attempt to improve the management of this poisoning. At the same time, it has been possible to record the electro- cardiographic and biochemical features of this condition and to compare them with published descriptions of digitalis overdose.

\section{Methods}

PATIENTS AND STUDY SITES

Patients were seen on admission to the medical wards of Anuradhapura General Hospital during June to September 1995 and December to

Table 1 Cardiac arrhythmias (\%) in 351 patients with yellow oleander poisoning who were admitted to a secondary hospital in Sri Lanka or transferred from the north of the island to the tertiary centre in Colombo

\begin{tabular}{lcl}
\hline Cardiac rhythm & $\begin{array}{l}2^{\circ} \text { Hospital } \\
(n=118)\end{array}$ & $\begin{array}{l}3^{\circ} \text { Centre } \\
(n=233)\end{array}$ \\
\hline Sinus rhythm & 43 & 40 \\
Sinus bradycardia & 19 & 14 \\
Sinus arrest or exit block & 16 & 16 \\
Atrial fibrillation & 1 & 0.5 \\
Atrial flutter & 0 & 1 \\
Junctional rhythm & 2 & 1 \\
Junctional bradycardia & 0 & 1 \\
Junctional rhythm with block & 0 & 0.5 \\
Supraventricular tachycardia & 3 & 6 \\
1st degree AV block & 3 & 6 \\
2nd degree AV block & 13 & 13 \\
3rd degree AV block & 7 & 8 \\
Bundle branch block & 1 & 0.5 \\
Ventricular ectopics & 2 & 2 \\
Ventricular tachycardia & 0 & 1 \\
Ventricular fibrillation & 0 & 0.5 \\
Not recorded & 6 & 2
\end{tabular}

$2^{\circ}$, secondary; $3^{\circ}$, tertiary referral centre. 
Table 2 Concentrations of serum cardiac glycosides, potassium, and magnesium in patients either discharged well from Anuradhapura, transferred from Anuradhapura to Colombo, or recruited to the RCT in Colombo CCU with relatively severe cardiotoxicity

\begin{tabular}{|c|c|c|c|}
\hline & \multicolumn{2}{|l|}{ Anuradhapura } & \multirow[b]{2}{*}{$\begin{array}{l}\text { Colombo CCU } \\
\text { Severe toxicity }\end{array}$} \\
\hline & Discharged well & $\begin{array}{l}\text { Transferred to } \\
C C U\end{array}$ & \\
\hline Cardiac glycosides $(\mathrm{nmol} / \mathrm{l})$ & $1.49(0.96)$ & $3.00(1.25)$ & $2.83(0.73)$ \\
\hline Range & 0 to 4.1 & 0 to 6.1 & 1.25 to 4.62 \\
\hline Potassium (mmol/l) & $4.3(0.8)$ & $5.4(1.3)$ & $4.9(1.1)$ \\
\hline Range & 2.9 to 7.2 & 3.2 to 10.8 & 2.6 to 8.4 \\
\hline Magnesium (mmol/1) & $0.82(0.12)$ & $0.83(0.11)$ & $0.76(0.13)$ \\
\hline Range & 0.54 to 1.09 & 0.62 to 1.08 & 0.41 to 1.08 \\
\hline
\end{tabular}

Values are mean (SD) and range.

March 1997, and to the coronary care unit (CCU) of the Institute of Cardiology, Colombo, during March to October 1997. Anuradhapura General Hospital is the primary health centre for the town and a wide area surrounding it. It is also the secondary hospital for the 750000 people who live in Anuradhapura District, receiving all oleander poisoned patients who present to rural clinics and small hospitals across the district. The CCU in Colombo is the tertiary cardiology centre with facilities for temporary pacing for the whole island.

In Anuradhapura, an ECG was taken during the standard work up of each patient or, when no ECG machine was available, the cardiac rhythm was recorded from a three lead monitor.

Patients were seen in Colombo as part of a trial of polyclonal antidigoxin Fab in oleander poisoning (Eddleston $\mathrm{M}$ et al, submitted for publication). Every patient admitted to the CCU with oleander poisoning was seen by one of the study team and an ECG recorded. Patients with second or third degree AV block, sinus bradycardia $<40$ beats/min, sinus arrest or exit block, or atrial tachyarrhythmias were considered to be severely poisoned and recruited to the study.

BIOCHEMISTRY

A blood sample was taken on admission from each patient in Anuradhapura and from Colombo patients recruited to the randomised controlled trial. All samples were centrifuged within 60 minutes; the serum was taken off and stored at $-20^{\circ} \mathrm{C}$. Samples were transferred on dry ice and thawed only once, immediately before analysis.

A biochemical screen was performed in the clinical laboratory of Homerton Hospital, London, using standard automated techniques. Digoxin cross reactive serum cardiac glycosides were measured using a polarisation fluoroimmunoassay for digoxin (InnofluorDigoxin Assay system, Oxis International Inc, Portland, Oregon, USA on the Abbot TDx machine).

\section{Results}

PRIMARY AND SECONDARY LEVELS OF HEALTH CARE (ANURADHAPURA GENERAL HOSPITAL) ECGs and blood samples were taken from 118 patients presenting to Anuradhapura General Hospital with a history of yellow oleander seed ingestion. Patients were young (mean age 23.9 years); $57 \%$ were female. Almost all had previously been in good health; only one reported taking regular drug treatment, a 17 year old girl with rheumatic heart disease on $0.25 \mathrm{mg}$ digoxin/day.

A normal ECG was found on presentation in $43 \%$. Many of the other patients showed conduction abnormalities of the sinus node or AV node (table 1). Some patients had been transferred to Anuradhapura on isoprenaline drips and were tachycardic on admission.
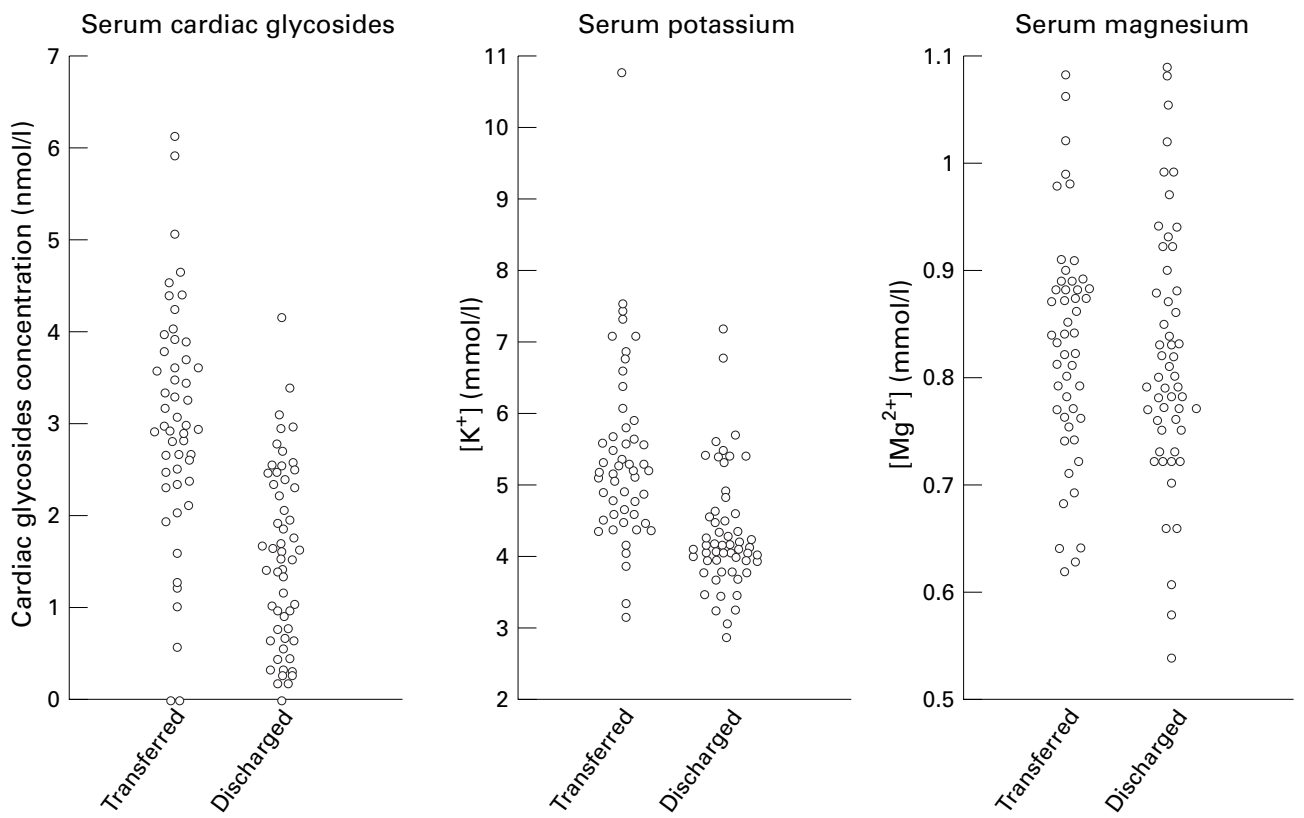

Figure 1 Serum concentrations of cardiac glycosides, potassium, and magnesium in patients admitted to Anuradhapura General Hospital who were then either transferred to Colombo or discharged without specific treatment. There was a great deal of overlap between the two groups, particularly with potassium and magnesium, which suggests that neither of these electrolytes will be good early markers of toxicity. The patient with a potassium of $10.8 \mathrm{mmol} / \mathrm{l}$ was rapidly transferred but died en route to Colombo. 
Table 3 Comparison of cardiac arrhythmias in patients with severe yellow oleander induced poisoning and those with either accidental or intentional digoxin overdose

\begin{tabular}{|c|c|c|c|c|c|}
\hline \multirow[b]{2}{*}{ Cardiac rhythm } & \multicolumn{5}{|c|}{ Frequency (\%) } \\
\hline & $\begin{array}{l}\text { Oleander } \\
\text { intentional } \\
(n=89)\end{array}$ & $\begin{array}{l}\text { Digoxin, }{ }^{11} \\
\text { intentional } \\
(n=70)\end{array}$ & $\begin{array}{l}\text { Digoxin, }{ }^{12} \\
\text { accidental No } 1 \\
(n=926)\end{array}$ & $\begin{array}{l}\text { Digoxin, }{ }^{13} \\
\text { accidental No } 2 \\
(n=101)\end{array}$ & $\begin{array}{l}\text { Digoxin, }{ }^{14} \\
\text { accidental No } 3 \\
(n=43)\end{array}$ \\
\hline Sinus bradycardia & 25 & NR & 4 & NR & 26 \\
\hline Sinus exit block/arrest & 62 & 10 & 2 & 1 & 19 \\
\hline Atrial fibrillation & 3 & 16 & 11 & 14 & 12 \\
\hline Atrial flutter & 1 & 4 & 1 & NR & NR \\
\hline Atrial tachycardia ( \pm block) & 3 & 23 & 11 & 8 & 2 \\
\hline Junctional rhythm & 3 & NR & 3 & 17 & 21 \\
\hline Junctional bradycardia & 20 & NR & NR & NR & NR \\
\hline Junctional tachycardia & 0 & 0 & 11 & NR & NR \\
\hline Junctional rhythm with block & 6 & NR & 0 & NR & NR \\
\hline 1st degree AV block & NR & 41 & 10 & NR & 33 \\
\hline 2nd or 3rd degree AV block & 53 & 57 & 20 & 8 & 33 \\
\hline (2nd/3rd degree) & $(38 / 21)$ & $(34 / 23)$ & $(11 / 9)$ & NR & NR \\
\hline Bundle branch block & 1 & 1 & NR & NR & NR \\
\hline Ventricular ectopics & 8 & 33 & 52 & 40 & 16 \\
\hline Ventricular tachycardia & 1 & 17 & 9 & 12 & 7 \\
\hline Ventricular fibrillation & 0 & 13 & $<1$ & 0 & 3 \\
\hline SA and AV block & 30 & NR & NR & 1 & NR \\
\hline
\end{tabular}

$\mathrm{AV}$, atrioventricular; NR, not reported; SA, sinoatrial.

The Anuradhapura physicians transferred all patients with second or third degree AV block, marked sinus bradycardia, or atrial tachyarrhythmias to the CCU in Colombo. Potassium levels were not measured before transfer; all decisions were based only on the heart rhythm.

Mean serum digoxin cross reactive cardiac glycoside and potassium concentrations (table 2) were significantly higher in patients who were transferred: $3.00 \mathrm{nmol} / 1$ cardiac glycoside $v 1.49 \mathrm{nmol} / 1$, and $5.4 \mathrm{mmol} / 1$ potassium $v 4.3$ $\mathrm{mmol} / 1$ (both $\mathrm{p}<0.0001$; Student's $t$ test). Mean serum magnesium concentrations were not different between the two groups: 0.83 $\mathrm{mmol} / 1$ v $0.82 \mathrm{mmol} / \mathrm{l}(\mathrm{p}=0.64)$. However, there was a large degree of overlap between the groups for all three assays (fig 1).

A biochemical screen was performed in a subset of 53 patients (the last 53 seen during the summer of 1995). Creatine kinase (CK) was raised in 14 patients (range 203 to 1124 IU/1); however, this was not related to the severity of cardiotoxicity (CK 201.3 IU/1 in patients who were transferred or died $v 202.8$ IU/1 in patients who were discharged without specialised treatment). Liver enzymes were normal in 49 patients; three had mildly increased values while one had a $\gamma$ glutamyl transferase value of $1112 \mathrm{IU} / 1$ and an aspartate

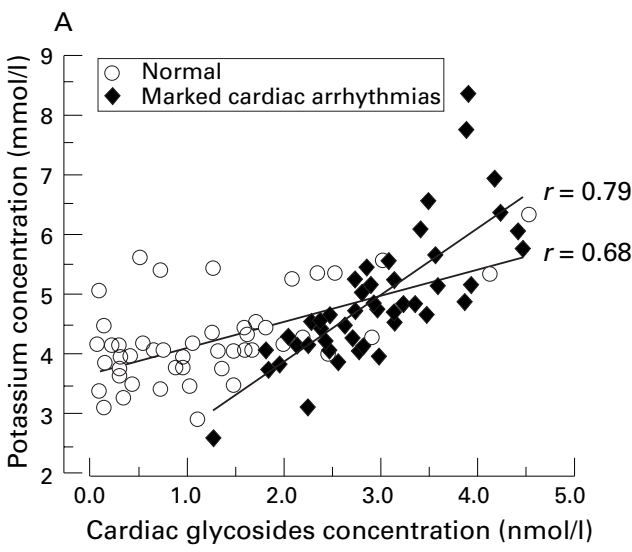

transaminase of $101 \mathrm{IU} / 1$. Creatinine and urea were raised in one patient (a 70 year old man); urea alone was raised in three patients. Random blood glucose was greater than 11 $\mathrm{mmol} / 1$ in six patients (range 11.2 to 38.3 $\mathrm{mmol} / \mathrm{l})$. Serum proteins were within the normal range in all 53 patients.

\section{OUTCOMES}

Two patients died and 52 required transfer to the Colombo CCU. At least one died during transit. The other 64 patients were treated symptomatically and discharged well. Four other patients died on arrival before either blood sample or ECG could be taken and are not discussed further here. Serum samples were taken from two of the patients who died in hospital and from the patient who died en route to Colombo. Two of them showed marked electrolyte disturbances.

KD019 was a 16 year old girl who, on presentation five hours after eating eight seeds, had third degree heart block and a cardiac glycoside concentration of $22 \mathrm{nmol} / \mathrm{l}$, serum potassium of $8.3 \mathrm{mmol} / \mathrm{l}$, and serum magnesium of $1.34 \mathrm{mmol} / 1$. KD025 was a man who presented three hours after eating five seeds with sinus and AV node conduction defects and cardiac glycoside concentration of 5.91

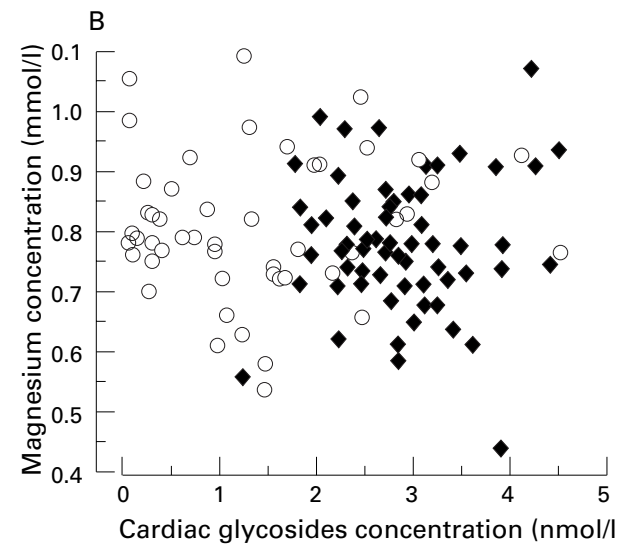

Figure 2 Relation of serum potassium and magnesium concentrations to serum cardiac glycoside concentration in the serum of patients with normal ECGs or relatively severe cardiotoxicity. 
Table 4 Concentrations of serum cardiac glycosides, potassium, and magnesium in patients recruited to the randomised controlled trial in Colombo CCU with either AV block, sinus block, or both $A V$ and sinus block

\begin{tabular}{llll}
\hline & AV block & Sinus block & AV and sinus block \\
\hline Cardiac glycosides (nmol/1) & $2.88(0.86)$ & $2.68(0.57)$ & $3.10(0.56)$ \\
$\quad$ Range & 1.25 to 4.46 & 1.82 to 3.84 & 2.24 to 4.16 \\
Potassium (mmol/1) & $4.9(1.1)$ & $4.6(0.5)$ & $5.1(1.2)$ \\
$\quad$ Range & 2.6 to 7.8 & 3.8 to 5.7 & 3.1 to 8.4 \\
$\quad \begin{array}{ll}\text { Magnesium (mmol/l) } \\
\quad \text { Range }\end{array}$ & $0.82(0.13)$ & $0.77(0.09)$ & $0.76(0.12)$ \\
& 0.44 to 0.97 & 0.59 to 0.99 & 0.61 to 1.07 \\
\hline
\end{tabular}

Values are mean (SD) and range.

$\mathrm{AV}$, atrioventricular; CCU, coronary care unit.

$\mathrm{nmol} / \mathrm{l}$, serum potassium of $10.8 \mathrm{mmol} / \mathrm{l}$, and serum magnesium of $1.05 \mathrm{mmol} / \mathrm{l}$. He died en route to Colombo. KD046 was a seventeen year old boy who presented, eight hours after eating two seeds, with second degree AV node block, cardiac glycoside concentration of 4.93 $\mathrm{nmol} / \mathrm{l}$, serum potassium of $5.9 \mathrm{mmol} / \mathrm{l}$, and serum magnesium of $0.84 \mathrm{mmol} / \mathrm{l}$.

\section{TERTIARY LEVEL OF HEALTH CARE (CCU COLOMBO)}

Two hundred and thirty three patients with a history of yellow oleander poisoning were seen in the Colombo CCU after transfer from secondary hospitals in the north of the island. Most patients were young (mean age 24.6 years, range 10 to 67 ) and previously fit. Fifty nine per cent of the patients were female. A past medical history was taken from the trial patients: one 16 year old boy had a diagnosis of asthma but was not receiving treatment; all other patients had been well previously.

The cardiac rhythms of these patients on admission are given in table 1 . Although most patients had shown typical arrhythmias in the peripheral hospitals, $40 \%$ had reverted back to regular sinus rhythm by the time they arrived in the CCU. Relatively few patients showed marked cardiotoxicity on admission, but some progressed from normal ECGs to AV conduction blocks or sick sinus syndrome over the following hours, possibly owing to continuing absorption of cardiac glycosides from the gastrointestinal tract.

\section{PATIENTS WITH RELATIVELY SEVERE}

CARDIOTOXICITY

The 89 patients recruited to the trial had relatively severe cardiotoxicity. The most common

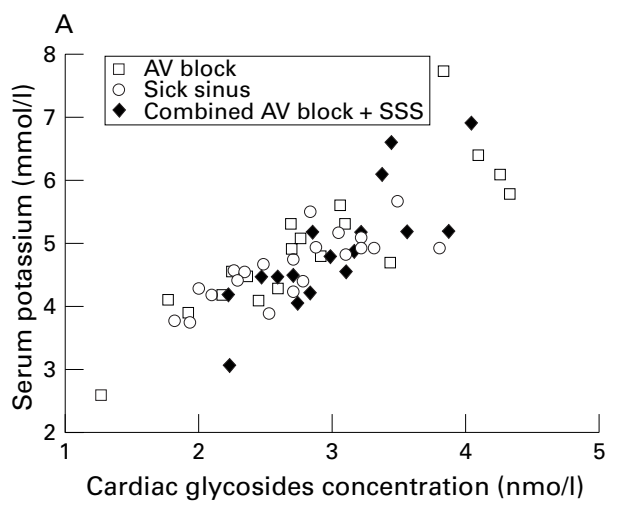

arrhythmias were conduction defects affecting the sinus node (sinus bradycardia in 25\%; sinus arrest or exit block in $62 \%$ ) or the AV node (second or third degree heart block in $53 \%$ ). Thirty per cent of patients had marked involvement of both sinus and AV nodes (table 3).

Electrolyte and serum cardiac glycoside concentrations were measured in 88 of these patients (blood samples could not be taken from one patient who died). The mean values for digoxin cross reactive cardiac glycosides, potassium, and magnesium are given in table 2 .

\section{CARDIAC RHYTHM AND SERUM CARDIAC}

GLYCOSIDE AND ELECTROLYTE CONCENTRATIONS To investigate the relation between serum cardiac glycoside levels, electrolyte concentrations, and cardiac rhythm, 50 patients seen in Anuradhapura with normal ECGs were compared with 63 patients with marked arrhythmias who were treated in Colombo. Serum cardiac glycoside concentrations were plotted against serum potassium (fig $2 \mathrm{~A}$ ) and magnesium (fig 2B) for the members of each group.

There was a clear relation between serum cardiac glycosides and potassium concentrations. There was an overall correlation of $r=0.70$ between cardiac glycoside and potassium for all 113 patients; analysing the patients with normal rhythms and those with abnormal rhythms separately gave values of $r=0.68$ and $r=0.79$, respectively (no significant difference between these values). There was no correlation between serum magnesium and cardiac glycosides for all the patients taken together or for the two groups.

The patients with marked arrhythmias were then grouped according to whether the arrhythmia affected the AV node (20 patients), sinus node ( 25 patients), or both AV and sinus nodes (18 patients). The mean serum cardiac glycoside, potassium, and magnesium concentrations were then calculated (table 4). Serum cardiac glycoside levels were plotted against serum potassium (fig 3A) and magnesium (fig 3B) concentrations for the members of these groups. There was no apparent relation between the site of conduction block and the serum cardiac glycoside or electrolyte values. However, the mean serum cardiac glycoside concentration was significantly higher in patients with both $\mathrm{AV}$ and

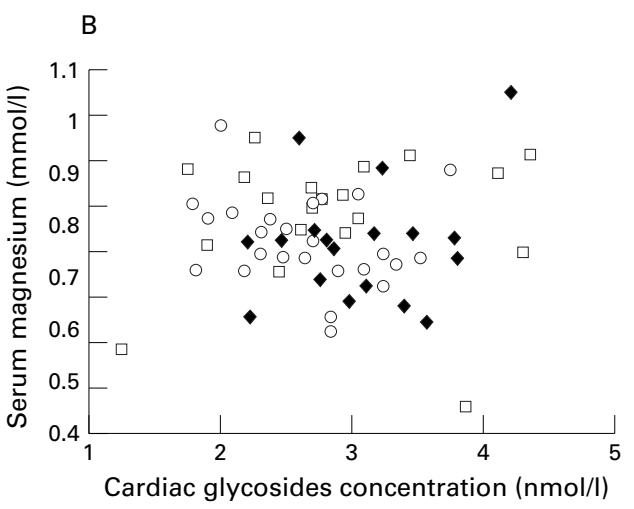

Figure 3 Relation between serum cardiac glycoside concentration and (A) potassium concentration and (B) magnesium concentration in relation to cardiac abnormality on presentation to Colombo coronary care unit. 
sinus node block than in patients with block affecting only the sinus node ( $p=0.016$; analysis of variance).

\section{Discussion}

This epidemic of yellow oleander poisoning in northern Sri Lanka has provided an opportunity to study in detail an uncommon poisoning that occurs in many parts of the tropical world. All but one of the previous reports had presented fewer than 13 cases $^{2}$; one report of 170 cases included no ECG or biochemical data. ${ }^{4}$ The present study of 351 patients is the first to provide this information.

Yellow oleander poisoning resembles digoxin poisoning. However, the mean age of patients admitted with accidental digoxin overdose in the industrialised world is much older than the patients taking oleander seeds: 75 years in one study of 219 American patients ${ }^{14}$ compared with 24.8 years for 415 Sri Lankan oleander patients. ${ }^{9}$ Even among a French series of attempted suicides with digoxin, where one might expect patients to be younger, only $29 \%$ were less than 40 years and $39 \%$ were older than 60 years. ${ }^{11}$

Most of our patients were healthy before they ate the seeds. This differs markedly from patients with digoxin poisoning: of 66 deliberate self harm patients in the French study, more than $90 \%$ had a pre-existing heart condition. ${ }^{11}$ Similarly, the majority of patients with accidental overdose are on multiple drug treatment: $58 \%$ of patients in one study were taking three or more drugs in addition to digoxin. ${ }^{14}$ As a result of the patients' young age and previously healthy state, the cardiac arrhythmias induced by oleander poisoning are unlikely to result from pre-existing conditions. ${ }^{5} 1315$

Most symptomatic patients had conduction defects affecting the sinus or AV node; in 30\% of the severe cases both nodes were significantly affected (table 2). Both AV conduction block and sinus dysfunction were overrepresented in these patients owing to selection bias compared with previous series of digoxin poisoning. However, the unreliability of the lists of digoxin associated arrhythmias has been emphasised by Fisch and Stone. ${ }^{12}$ They noted the lack of control groups, their retrospective nature, the variation in the physicians' ability to distinguish particular arrhythmias, and the difficulty of distinguishing digoxin related arrhythmias from those caused by the underlying defect requiring the digoxin treatment. The prospective nature of the current study, together with health of its subjects, reduces the force of these criticisms.

Rhythms characteristic of Mobitz type II AV conduction block, although reported to be rare in isolated digoxin poisoning, ${ }^{15}$ occurred in several of the oleander patients (see fig 3 in reference 9). Atrial fibrillation and flutter were uncommon in our patients, again probably because of their good pre-existing cardiac status. The four patients in our series with these arrhythmias all presented with a slow ventricular response owing to impaired $\mathrm{AV}$ conduction, as occurs in digoxin poisoning. ${ }^{5} 15$
The patients treated with antidigoxin Fab reverted back to normal sinus rhythm (Eddleston $M$ et al, unpublished data, 1999), suggesting that these atrial arrhythmias had not been present before the poisoning. Ventricular ectopic beats were uncommon in the oleander patients.

Hyperkalaemia exacerbates cardiac glycoside induced cardiac arrhythmias and is a marker of a poor outcome in cardiac glycoside poisoning. Even though all symptomatic patients had persistent vomiting, severe yellow oleander induced cardiotoxicity was associated with hyperkalaemia. The degree of hyperkalaemia correlated with the serum digoxin cross reactive cardiac glycoside concentration (fig 2).

The French study of suicidal digoxin overdoses also found an association between hyperkalaemia and cardiotoxicity: the mean (SD) admission serum potassium concentration for patients who died was $6.15(0.74)$ $\mathrm{mmol} / \mathrm{l}$ compared with $4.2(0.52)$ for patients who recovered. ${ }^{11}{ }^{16}$ The authors suggested that serum potassium levels would be a rapid marker of patients with a poor prognosis. ${ }^{16}$

Serum cardiac glycoside and potassium concentrations were significantly higher in patients transferred to Colombo for specialised care than in those discharged directly from Anuradhapura. Unfortunately, we did not find serum potassium to be a specific early marker of patients who would require transfer (fig 1). Ten of 54 patients who were managed symptomatically in Anuradhapura without transfer had serum potassium values $>5.0 \mathrm{mmol} / 1$ on admission. The potassium and cardiac glycoside levels were not higher in patients recruited to the trial than in those who required transfer from Anuradhapura to the CCU. This may be because patients with markedly raised potassium or cardiac glycosides died before reaching Colombo.

Accidental digoxin poisoning in elderly patients taking therapeutic digoxin is often complicated by hypokalaemia owing to combined treatment with diuretics. ${ }^{13}{ }^{15}$ This is an uncommon problem in both yellow oleander poisoning and suicidal digoxin overdose. ${ }^{11} 16$ However, three patients who presented to Colombo with severe poisoning had serum potassium concentrations less than $3.0 \mathrm{mmol} / 1$; one of these patients died (Eddleston $\mathrm{M}$ et al, unpublished data, 1999). Further studies will be required to see whether early potassium assay and correction improves outcome.

Hypomagnesaemia predisposes to digoxin toxicity. ${ }^{13} 15$ We found no relation between serum magnesium with either arrhythmia or cardiac glycoside concentration. This suggests that serum magnesium concentrations are not altered by yellow oleander poisoning but does not preclude the possibility that abnormally high or low magnesium levels before the poisoning might affect the outcome. Two of the three fatalities from whom we were able to get blood samples had hypermagnesaemia (1.08 and $1.34 \mathrm{mmol} / \mathrm{l}$ ). One patient who was treated in the clinical trial but died had a serum magnesium concentration of $0.47 \mathrm{mmol} / 1$. 
We were unable to identify a clear relation between a patient's arrhythmia at presentation and the serum glycoside concentration or electrolyte disturbance. Future studies will need to assess the relative importance of cardiac glycoside levels and electrolyte disturbances at presentation as determinants of mortality.

We thank the staff of Anuradhapura General Hospital and Institute of Cardiology for the help during the course of these studies, and Douglas Chamberlain for his comments on the manuscript. The work was supported by the Association of Physicians (Links

1 Pearn J. Oleander poisoning. In: Covacevich J, Davine P, Pearn J, eds. Toxic plants and animals: a guide for Australia, Pearn J, eds. Toxic plants and animals: a guide for

2 Langford SD, Boor PJ. Oleander toxicity: an examination of the human and animal toxic exposures. Toxicology 1996; 109:1-13.

3 Sreeharan N, Putharasingam S, Ranjadayalan K, et al. Yellow oleander poisoning-clinical manifestations and prognostic criteria. Faffna Med $\mathcal{F}$ 1985;20:100-1

4 Saravanapavananthan N, Ganeshamoorthy J. Yellow oleander poisoning - a study of 170 cases. Forensic Sci Int 1988; 36:247-50.

5 Fisch C, Surawicz B, eds. Digitalis. New York: Grune and Stratton, 1969.
6 Shaw D, Pearn J. Oleander poisoning. Med 7 Aust 1979;2:267-9.

7 Brewster D. Herbal poisoning: a case report of a fatal yellow oleander poisoning from the Solomon islands. Ann Trop Paediatr 1986;6:289-91.

8 Haynes BE, Bessen HA, Wightman WD. Oleander tea: herbal draught of death. Ann Emerg Med 1985;14:350-3.

9 Eddleston M, Ariaratnam CA, Meyer PW, et al. Epidemic of self-poisoning with seeds of the yellow oleander tree (Thevetia peruviana) in northern Sri Lanka. Trop Med Int Health vetia peruviana)

10 Eddleston M, Sheriff MHR, Hawton K. Deliberate self-harm in Sri Lanka: an overlooked tragedy in the developing world. BMF 1998;317:133-5.

1 Gaultier M, Fournier E, Efthymiou ML. Intoxication digitalique aigue (70 observations). Bull Soc Med Hop Paris 1968;119:247-74.

12 Fisch C, Stone JM. Recognition and treatment of digitalis toxicity. In: Fisch C, Surawicz B, eds. Digitalis. New York: Grune and Stratton, 1969

13 Smith TW, Antman EM, Friedman PL, et al. Digitalis glycosides: mechanisms and manifestations of toxicity (parts I-III). Prog Cardiovasc Dis 1984;26:413-58, 495540; 27:21-56.

14 Mahdyoon H, Battilana G, Rosman H, et al. The evolving pattern of digoxin intoxication: observations at a large urban hospital from 1980 to 1988. Am Heart f 1990;120: 1189-94

15 Kelly RA, Smith TW. Recognition and management of digitalis toxicity. Am f Cardiol 1992;69:108-19G.

16 Bismuth C, Gaultier M, Conso F, et al. Hyperkalaemia in acute digitalis poisoning: prognostic significance and therapeutic implications. Clin Toxicol 1973;6:153-62. 